\title{
Research survey suggests opportunities
}

\section{Diane Cooper, AHIP}

See end of article for author's affiliation.

DOI: http://dx.doi.org//10.3163/1536-5050.104.2.014

Six hundred twenty-four members of the Medical Library Association (MLA) took the time to respond to a survey about what they did and thought in their own research lives. Results are reported in this issue [1]. This impressive research presentation deserves some comment.

First, we have to consider who filled out the survey. The response rate was less than $20 \%$, meaning that 4 out of 5 MLA members did not respond. Who are these nonresponders? We can only speculate. My guess is they compose 2 groups: some too busy to take the relatively short survey (34 questions) and the rest just not interested in surveys about research. My estimate is the second was the larger group. They are probably younger, too. Most of those who did respond were more than 10 years out from their library degrees.

Which means that interest in research and barriers to research that the survey found may not represent MLA membership in general. The other four out of five members may have totally different viewpoints. And opinions may have changed since the survey was done five years ago. Caution in interpretation of surveys is always wise.

Still, there were some interesting findings. The researchers divided results into two groups, academics versus hospital librarians. An "Other" group was included but was too diverse to categorize. Most respondents read research literature at least between once a week and once a month. They generally felt that research had benefits for library decision making, to guide collections and improve or initiate new services. They also agreed that research can demonstrate library value to funding authorities.

Because the academic environment is generally more supportive of research, it was no surprise that academics were more likely than hospital librarians to conduct research, present posters or papers at professional meetings, and apply for grants. Barriers to doing research were similar, except hospital librarians were much more likely to be restricted by lack of time.

\section{OPPORTUNITIES}

Many respondents admitted they had "very little skill" in using common statistical techniques. About half felt less skilled in assessing validity of statistical results. Hospital librarians were more likely to profess having little skill in ability to obtain outside funding.

\section{IMPLICATIONS}

What does this all mean? You can decide for yourself; the data are presented in the paper and online. To me, it suggests that providing statistical and analytical support to those members who are interested in research could improve research productivity, and we could all benefit. Help writing grant applications and finding funding would help, too. But we need to find out more about how younger MLA members feel and what they want. We need to find out if the missing four out of five members would have more interest in research if it were better communicated. In research, the better the communication, the more the impact. Help in research communication would probably also be widely appreciated.

\section{REFERENCE}

1. Lessick S, Perryman C, Billman BL, Alpi KM, De Groote SL, Babin Jr. TD. Research engagement of health sciences librarians: a survey of research-related activities and attitudes. J Med Libr Assoc. 2016 Apr;104(2):166-73.

\section{AUTHOR'S AFFILIATION}

I. Diane Cooper, AHIP, jmlaeditorbox@gmail.com, Editor-in-Chief, Journal of the Medical Library Association 